\title{
An unexpected twist: Sperm cells coil to the right in land snails and to the left in song birds
}

\author{
Menno Schilthuizen ${ }^{1,2^{*}}$, Rob Langelaan ${ }^{1}$, Nicola Hemmings ${ }^{3}$, Wesley van Oostenbrugge ${ }^{1,4}$, Stefan Visser $^{1,4}$ \\ ${ }^{1}$ Naturalis Biodiversity Center, Darwinweg 2, 2333CR Leiden, the Netherlands \\ ${ }^{2}$ Institute Biology Leiden, Leiden University, Sylviusweg 72, 2333BE Leiden, the Netherlands \\ ${ }^{3}$ Department of Animal and Plant Sciences, University of Sheffield, Western Bank, Sheffield S10 2TN, UK \\ ${ }^{4}$ Forensic Science Dept., Amsterdam University of Applied Sciences, Weesperzijde 190, 1097 DZ Amsterdam, the \\ Netherlands \\ *Corresponding author: menno.schilthuizen@naturalis.nl
}

Keywords: Gastropoda, Passeriformes, spermatozoa, chirality, dextral, sinistral

\begin{abstract}
In animals, cell polarity may initiate symmetry breaking very early in development, ultimately leading to whole-body asymmetry. Helical sperm cells, which occur in a variety of animal clades, are one class of cells that show clearly visible bilateral asymmetry. We used scanning-electron microscopy to study coiling direction in helical sperm cells in two groups of animals that have figured prominently in the sperm morphology literature, namely land snails, Stylommatophora (514 spermatozoa, from 27 individuals, belonging to 8 species and 4 families) and songbirds, Passeriformes (486 spermatozoa, from 26 individuals, belonging to 18 species and 8 families). We found that the snail sperm cells were consistently dextral (clockwise), whereas the bird sperm cells were consistently sinistral (counterclockwise). We discuss reasons why this apparent evolutionary conservatism of sperm cell chirality may or may not be related to whole-body asymmetry.
\end{abstract}

\section{Contents}

Introduction ........................................................................ 297

Materials and Methods ………………………..................... 299

Snails and slugs: materials ............................................. 299

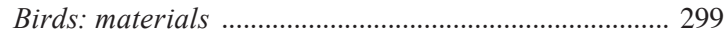

Scanning electron microscopy ..................................... 299

Results ....................................................................... 299

Discussion ........................................................................ 300

Acknowledgements ............................................................ 301

References .................................................................... 301

\section{Introduction}

When three-dimensional structures are bilaterally asymmetric, they become chiral, meaning that the two mirror-images cannot be superimposed. In animal body forms, chirality, either external, internal, or both, is a near-ubiquitous feature (reviewed in, for example, Ludwig, 1932; McManus, 2004). Well-known examples are coiled snails, claw asymmetry in crabs, eye torsion in flatfish, and vertebrate internal visceral organisation. However, the evolutionary developmental biology of symmetry breaking remains poorly understood (Palmer, 2004; Schilthuizen 2013; Davison et al., 2016).

Some symmetry-breaking developmental cascades have been partially resolved (Grande and Patel, 2009; Basu and Brueckner, 2008; Frasnelli et al., 2012). However, most of these occur at a relatively advanced stage of development, and evidence is mounting that the actual onset of symmetry breaking takes place much earlier in development and involves chiral molecules involved in the cytoskeleton (Brown and Wolpert, 1990; Vandenberg and Levin, 2010). For example, Davison et al. (2016) showed that, in the pond snail, Lymnaea stagnalis (Linnaeus, 1758), and the frog, Xenopus laevis Daudin, 1802, the upstream action of formins, proteins that regulate the polymerization of cytoskeletal actin filaments (Evangelista $e t$ al., 2003), and, hence, cell polarity (Nelson, 2003), translated downstream into reversed or randomized whole-body chirality. These observations support the "F-molecule" hypothesis of Brown and Wolpert (1990), which suggests that a chiral molecule in the zygote sets in motion directionally asymmetric development during ontogeny, and that such a mechanism may be acting in animals generally (Oliverio et al., 2010). In gastropods, this would agree with the singlegene, delayed inheritance, in which the offspring's coiling is determined by the mother's, not by the offspring's genotype (Sturtevant, 1923; Schilthuizen and Davison, 2005). 

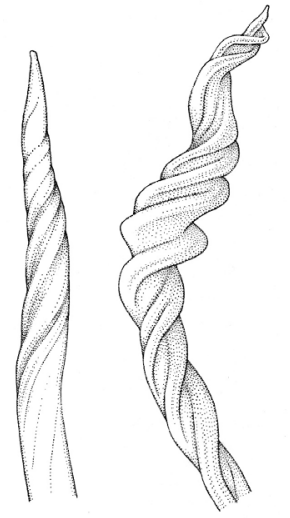

a

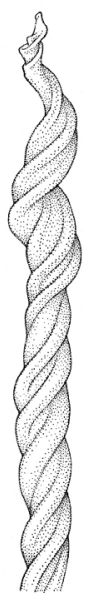

C

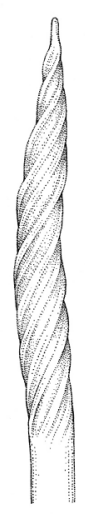

d

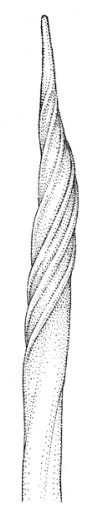

e

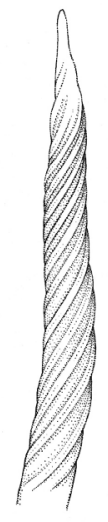

$f$

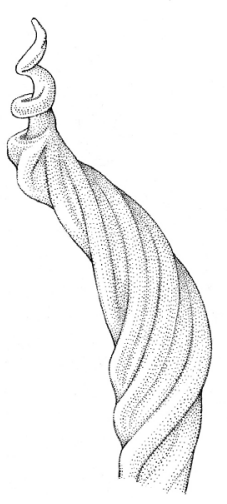

g
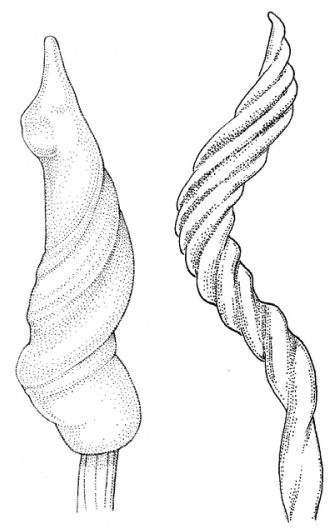

h i $\overline{2 \mu \mathrm{m}}$

Figure 1. Drawings of sperm cell heads of nine species of Pulmonata: a, Arianta arbustorum; b, Arion rufus; c, Arion subfuscus; d, Cepaea nemoralis; e, Cornu aspersum; f, Helix pomatia; g, Limax maximus; h, Succinea putris; i, Amphidromus inversus (a-h originals, drawn by Erik-Jan Bosch; i after Schilthuizen and van Heuven, 2011).

Evaluating if and how molecular, intracellular chirality may be connected to organismal chirality is laborious and time-consuming, especially if this is to be done across multiple species. Methods for rapid assessment of cell polarity would facilitate this work. Recently, techniques to visualise cellular chirality by allowing cell populations to grow on ring-shaped micropatterns (Wan et al., 2011) have become available. In some taxa, the striking morphology of mature sperm cells may also help. In many Mollusca, Gastrotricha, Kinorhyncha, Tardigrada, and in several groups of arthropods and vertebrates, spermatozoa have a helical structure (Ludwig, 1932; Baccetti and Afzelius, 1976; Jamieson, 2007), and cell polarity may be readily determined by inspection of their chirality. In helical asymmetry, the two mirror-image forms are called dextral, righthanded, or clockwise coiled (D) and sinistral, lefthanded, or anti-clockwise coiled (L), where helix coiling direction is determined by the rotation (clockwise or anti-clockwise) as the helix is traced starting at the end nearest the observer when viewed end-on. Systematic analyses of spermatozoon dextrality and/or sinistrality may provide further insights into connections between cytoskeleton chirality and asymmetric development.

During spermiogenesis of helical sperm cells, a sheath of microtubules forms, which subsequently develops into a microtubular helix that envelops the spiral acrosome and nucleus, and, in some cases, midpiece, and is then shed (Healy, 2001; Aire, 2014). It has been a matter of contention which molecular cell component drives the formation of this helical structure. Some authors have implicated the microtubular helix (e.g., Kondo et al., 1988). However, because the contact between the microtubuli and the spiral nucleus is minimal and transient, this is no longer considered tenable, and, instead, the crystalline conformation of DNAhistone molecules in the nucleus and/or the contents of the acrosome are currently thought to organise in a helical arrangement, with the microtubular helix secondary to that (Fawcett et al., 1971; Threadgold, 2017).

Although numerous studies have documented helical shape of sperm cells, few pay explicit attention to the coiling direction of these helices. In fact, as Ludwig (1932) lamented, a considerable number of authors seem to have been unconcerned about the true coiling direction of the sperm cells in their study organism, and have depicted either a left- or right-handed spiral based on personal preference rather than biological reality. Photographic images also do not often give a reliable indication of coiling direction. By their nature, transmission light or electron microscope images do not reveal whether a gyre is clockwise or anticlockwise, whereas scanning electron microscope images are sometimes mirror-imaged during the publication process (see Discussion). Consequently, very little reliable information is available on the degree of intraindividual, interspecific, and intraspecific variability in sperm cell coiling direction. 

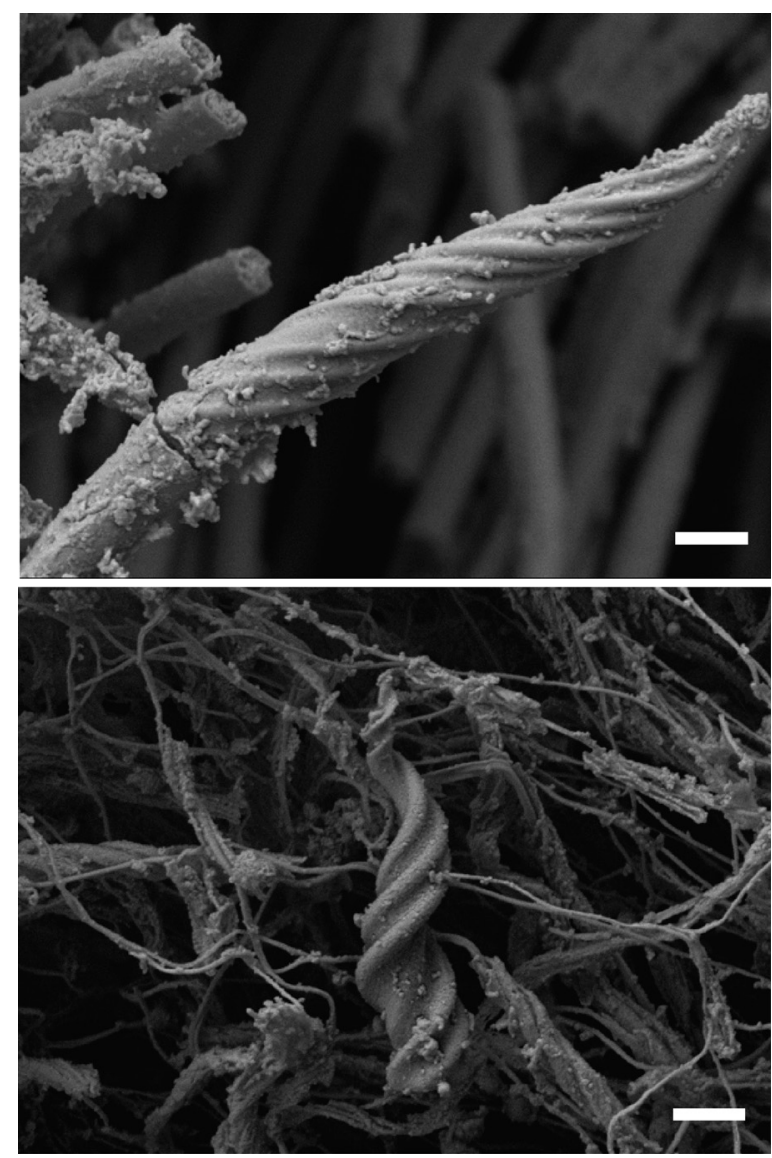

Figure 2. Scanning electron-micrographs of a sperm cell head among other sperm cells within a spermatophore for Cepaea nemoralis (top) and Arion subfuscus (bottom). Scale bar $=1 \mu \mathrm{m}$.

We therefore used scanning electron microscopy on relatively large numbers of mature sperm cells from multiple species of two taxa with helical sperm cells that have figured prominently in the sperm morphology literature, namely land snails and slugs (Stylommatophora) and songbirds (Passeriformes). With some provisos, we confirm Ludwig's (1932) suspicion that in land snails, spermatozoa appear to be consistently dextral, whereas in songbirds, they are sinistral.

\section{Materials and Methods}

\section{Snails and slugs: materials}

Stylommatophoran sperm cells are most easily obtained from the spermatophores that these hermaphroditic animals produce and transfer during mating. Therefore, adult, large-bodied snails and slugs were collected in several locations in the Dutch provinces of Zuid-Holland, Noord-Holland, and Flevoland during spring and early summer (when mating takes place) of 2014 and 2015. We collected animals that were found in copula, but also mature animals that may have recently mated and therefore contain fresh sperm in the spermatophore-receiving organ. All specimens were stored in $70 \%$ ethanol in the field. The animals were identified, dissected, and, when spermatophores were encountered, these were carefully removed and cut or broken lengthwise. The exposed halves were then dehydrated in an automated Leica EM CPD300 criticalpoint drier and affixed on stubs for scanning electron microscopy.

\section{Birds: materials}

We used Passeriformes sperm samples that had been preserved in 5\% formalin at the Department of Animal and Plant Sciences, University of Sheffield. These samples had been obtained for previous studies, using a range of techniques (as detailed in Birkhead et al., 1993; Immler and Birkhead, 2005, 2007). First, samples were cooled at $5^{\circ} \mathrm{C}$ overnight. Then, 10 $\mu 1$ of the pellet of the sample was placed directly on SEM stubs and air-dried for scanning electron microscopy.

\section{Scanning electron microscopy}

Sperm samples were coated with platinum/palladium ( $2 \mathrm{~nm}$ and $20 \mathrm{~nm}$ in the case of bird and snail sperm cells, respectively). Then, they were viewed in a JEOL JSM-7600F FEG-SEM, at magnifications up to $20,000 \times$. For each sample, we attempted to view and photograph at least 20 sperm cell heads. Coiling direction was determined by eye for each sperm cell. Using the letters embossed on the stub holders, it was confirmed that the image is not mirrored at any stage during the imaging process.

\section{Results}

For the Stylommatophora, we obtained photographs of 514 sperm cells, from 27 individuals, belonging to 8 species, and 4 families (SI1). Although sperm morphology varied considerably (Figs. 1,2), all cells, without exception coiled dextrally (SI2). For the Passeriformes, we obtained photographs of 486 sperm cells, from 26 individuals, belonging to 18 species, and 8 


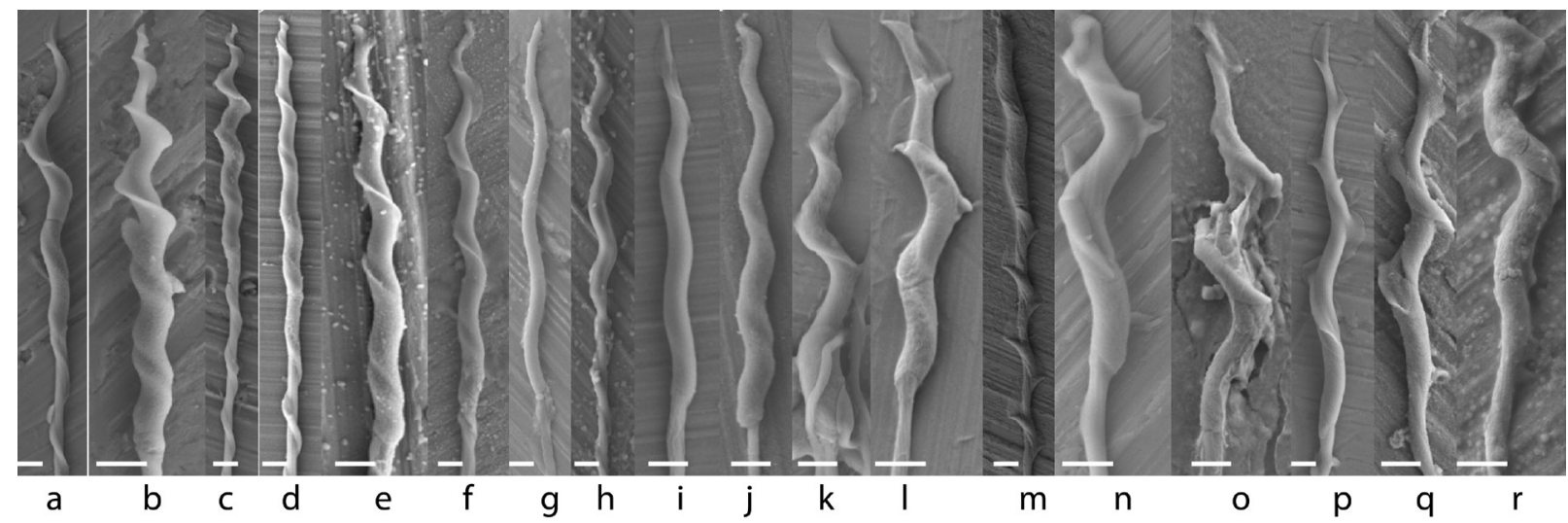

Figure 3. Scanning electron-micrographs of isolated sperm cell heads of various Passeriformes: a, Hippolais polyglotta; b, Hippolais icitrina; c, Acrocephalus scirpaceus; d, Phylloscopus sibilatrix; e, Phylloscopus collybita; f, Phylloscopus trochilus; g, Sylvia melanocephala; h, Sylvia atricapilla; i, Sylvia curruca; j, Cistothorus palustris; k, Prunella modularis; 1, Emberiza citrinella; m, Turdus merula; n, Fringilla coelebs; o, Acanthis cabaret; p, Chloris chloris; q, Carpodacus erythrinus; r, Haemorhous purpureus. All sperm cell heads have been shown with the tail down, and the acrosome up. Scale bars always represent $1 \mu \mathrm{m}$.

families (SI3). Here, overall morphology was more uniform (Fig. 3), all sperm cells coiled sinistrally (SI4).

\section{Discussion}

Our results suggest that sperm cell chirality is fixed in two large clades of animals: exclusively dextral in Stylommatophora, and exclusively sinistral in Passeriformes. Although we see interspecific differences in the number of gyres, the height of the crest, and the extent to which the helical structure dominates along the length of the acrosome, nucleus, midpiece, and tail, we found no indication of any intra-individual, intraspecific or interspecific variability in the direction of coiling. For Stylommatophora, this finding is consistent with the dextral sperm cells previously reported in the land snails Amphidromus inversus Müller, 1774, Arion hortensis (Férussac, 1819), Deroceras reticulatum (Müller, 1774), Tandonia sowerbyi (Férussac, 1823), and Anguispira alternata (Say, 1816) (Schilthuizen and van Heuven, 2011, and references therein).

For the Passeriformes, sinistrality has previously also been reported in, for example, Hirundo rustica Linnaeus, 1758, Turdus merula Linnaeus, 1758, Fringilla coelebs Linnaeus 1758, Sturnus vulgaris Linnaeus, 1758, and Poephila acuticauda (Gould, 1839) (Retzius, 1909; Vernon and Woolley, 1999; Hermosell et al., 2013; Rowe et al., 2015).

In contrast, a small number of papers depict stylommatophoran spermatozoa as sinistral helices (e.g.,
Maxwell, 1975, for Cornu aspersum (Müller, 1774), Selmi et al., 1989, for Oxyloma elegans (Risso, 1826)). Similarly, Birkhead and Immler (2007) depict a Passer domesticus (Linnaeus, 1758) sperm cell as a dextral helix. Because none of these papers explicitly state the chirality of their subjects, these inconsistencies could, in fact, be the result of inadvertent mirror-imaging of the scanning-electron micrographs. A more reliable deviation from our observations is Hickman (1931: 265), who states that in the amber snail Novisuccinea ovalis (Say, 1817), "there is no uniformity of direction of the spirals. [...] Out of many specimens examined, I find that the spirals may go in either a left or a right direction from head to tail, and that one condition is about as common as the other'. If confirmed by additional observations, this would suggest fixed coiling direction may be lost in some stylommatophoran lineages.

Despite the aforementioned deviations, and pending further investigations to augment the number of species and individuals sampled, we tentatively stress the uniformity in coiling direction of sperm cells in Stylommatophora and Passeriformes. It is tempting to speculate that such cellular homochirality is due to the same chiral cytoskeletal elements, such as actin filaments, that set in motion whole-body homochirality in the zygote (Levin and Palmer, 2007). Although, during spermiogenesis, the sperm cell nucleus retains little more than a near-crystalline DNA-histone-protamine complex, the acrosome, which, especially in birds, forms a considerable portion of the spiral sperm 
head, is known to contain actin filaments (e.g., Breitbart et al., 2005).

Another potentially relevant observation is that the sinistral and dextral sperm cells in birds (deuterostomes) and snails (protostomes) parallels the inversion of the antero-posterior and dorso-ventral axes in deuterostomes. The result in whole-body chirality is that the right of protostomes becomes the left in deuterostomes.

However, we doubt that such a one-to-one relation exists between spermatozoon homochirality and organismal homochirality. Two previous studies, by Selman and Waddington (1953) and Schilthuizen and van Heuven (2011), showed that snail species that are dimorphic for whole-body coiling direction (Radix labiata (Rossmässler, 1835) and Amphidromus inversus, respectively, which display both left-handed and right-handed shells), nonetheless always show dextral sperm. Similar studies have not yet been carried out in birds, where mirror-image reversal of the viscera is exceedingly rare (Palmer, 2004).

In conclusion, we suggest that a wider study of chirality in helical sperm cells in these and other taxa may prove a useful source for understanding symmetry breaking in development. We also suggest that studies of sperm morphology always explicitly record and identify the chirality of spiral structures and confirm that imaging methods did not yield inverted images.

\section{Acknowledgements}

We thank Tim Birkhead for providing samples, and Bertie-Joan van Heuven and Ewan Richardson for technical assistance. Three reviewers, Rich Palmer, Marco Oliverio, and Yumi Nakadera provided comments that helped us improve the paper. The specimens of Helix pomatia were collected under permission FF/75A/2010/021a from the Netherlands Ministry of Agriculture, Nature, and Food Quality.

\section{References}

Aire TA. 2014. Spermiogenesis in birds. Spermatogenesis 4(3): e959392.

Baccetti B, Afzelius BA. 1976. Biology of the sperm cell. Monographs on Developmental Biology 10.

Basu B, Brueckner M. 2008. Cilia: multi-functional organelles at the center of vertebrate left-right asymmetry. Current Topics in Developmental Biology 85: 151-174.

Birkhead TR, Immler S. 2007. Making sperm: design, quality control and sperm competition. Society of Reproduction and Fertility Supplement 65: 175-181.
Birkhead TR, Pellatt EJ, Fletcher F. 1993. Selection and utilization of spermatozoa in the reproduction tract of the female zebra finch Taeniopygia guttata. Journal of Reproduction and Fertility 99: 593-600.

Breitbart H, Cohen G, Rubinstein S. 2005. Role of actin cytoskeleton in mammalian sperm capacitation and the acrosome reaction. Reproduction 129: 263-268.

Brown NA, Wolpert L. 1990. The development of handedness in left/right asymmetry. Development 109: 1-9.

Davison A, McDowell GS, Holden JM, Johnson HF, Koutsovoulos GD, Liu MM, Hulpiau P, Van Roy F, Wade CM, Banerjee R, Yang F, Chiba S, Davey JW, Jackson DJ, Levin M, Blaxter ML. 2016. Formin is associated with left-right asymmetry in the pond snail and the frog. Current Biology 26: 654-660.

Evangelista M, Zigmond S, Boone C. 2003. Formins: signaling effectors for assembly and polarization of actin filaments. Journal of Cell Science 116: 2603-2611.

Fawcett DW, Anderson WA, Phillips DM. 1971. Morphogenetic factors influencing the shape of the sperm head. Developmental Biology 26: 220-251.

Frasnelli E, Vallortigara G, Rogers LJ. 2012. Left-right asymmetries of behaviour and nervous system in invertebrates. Neuroscience Biobehavioral Reviews 36: 1273-1291.

Grande C, Patel NH. 2009. Nodal signalling is involved in leftright asymmetry in snails. Nature 457: 1007-1011.

Healy JM. 2001. Spermatogenesis and oogenesis. In: Barker GM, ed. The biology of terrestrial mollusks. Wallingford: CABI Publishing, 357-382.

Hermosell IG, Laskemoen T, Rowe M, Møller AP, Mousseau TA, Albrecht T, Lifjeld JT. 2013. Patterns of sperm damage in Chernobyl passerine birds suggest a trade-off between sperm length and integrity. Biology Letters 9: 20130530.

Hickman CP. 1931. The spermiogenesis of Succinea ovalis Say, with special reference to the components of the sperm. Journal of Morphology and Physiology 51: 243-289.

Immler S, Birkhead TR. 2005. A non-invasive method for obtaining spermatozoa from birds. Ibis 147: 827-830.

Immler S, Birkhead TR. 2007. Sperm competition and sperm midpiece size: no consistent pattern in passerine birds. Proceedings of the Royal Society B 274: 561-568.

Jamieson BGM. 2007. Avian spermatozoa: structure and phylogeny. In: Jamieson BGM, ed. Reproductive biology and phylogeny of birds. Part A. Phylogeny, morphology and fertilization. Enfield: Science Publishers, 349-511.

Kondo T, Hasegawa K, Uchida TA. 1988. Formation of the microtubule bundle and helical shaping of the spermatid in the common finch, Lonchura striata var. domestica. Journal of Ultrastructure and Molecular Structure Research 98: 158168.

Levin M, Palmer AR. 2007. Left-right patterning from the inside out: Widespread evidence for intracellular control. BioEssays 29: 271-287.

Ludwig W. 1932. Das Links-Rechts Problem in Tierreich und beim Menschen. Berlin: Springer.

Maxwell WL. 1975. Scanning electron microscope studies of Pulmonate spermatozoa. Veliger, 18: 31-33.

McManus C. 2004. Right Hand, Left Hand. The Origins of Asymmetry in Brains, Bodies, Atoms and Cultures. Cambridge: Harvard University Press.

Nelson WJ. 2003. Adaptation of core mechanisms to generate cell polarity. Nature 422: 766-774. 
Oliverio M, Digilio MC, Versacci P, Dallapiccola B, Marino B. 2010. Shells and heart: Are human laterality and chirality of snails controlled by the same maternal genes? American Journal of Medical Genetics A 152A: 2419-2425.

Palmer AR. 2004. Symmetry breaking and the evolution of development. Science 306: 828-833.

Retzius G. 1909. Die Spermien der Vögel. Biologische Untersuchungen 14: 89-122.

Rowe M, Griffith SC, Hofgaard A, Lifjeld JT. 2015. Subspecific variation in sperm morphology and performance in the Long-tailed Finch (Poephila acuticauda). Avian Research 6: 23 .

Schilthuizen M. 2013. Something gone awry: unsolved mysteries in the evolution of asymmetric animal genitalia. Animal Biology 63: 1-20.

Schilthuizen M, Davison A. 2005. The convoluted evolution of snail chirality. Naturwissenschaften 92: 504-515.

Schilthuizen M, van Heuven BJ. 2011. Dextral and sinistral Amphidromus inversus (Gastropoda: Pulmonata: Camaenidae) produce dextral sperm. Zoomorphology 130: 283-287.

Selman GG, Waddington CH. 1953. The structure of the spermatozoa in dextral and sinistral races of Limnaea peregra. Quarterly Journal of Microscopical Science 94: 391-397.

Selmi MG, Bigliardi E, Giusti F. 1989. Morphological modifications in stored heterospermatozoa of Oxyloma elegans (Pulmonata: Stylommatophora). Journal of Ultrastructure and Molecular Structure Research 102: 82-86.

Sturtevant AH. 1923. Inheritance of direction of coiling in Limnaea. Science 58: 269-270.

Threadgold LT. 2017. The Ultrastructure of the Animal Cell: International Series in Pure and Applied Biology (Vol. 55). Amsterdam: Elsevier.

Vandenberg LN, Levin M. 2010. Far from solved: a perspective on what we know about early mechanisms of left-right asymmetry. Developmental Dynamics 239: 3131-3146.

Vernon GG, Woolley DM. 1999. Three-dimensional motion of avian spermatozoa. Cytoskeleton 42: 149-161.

Wan LQ, Ronaldson K, Park M, Taylor G, Zhang Y, Gimble JM, Vunjak-Novakovic G. 2011. Micropatterned mammalian cells exhibit phenotype-specific left-right asymmetry. Proceedings of the National Academy of Science USA 108: 12295-12300.

Received: 2 September 2017

Revised and accepted: 14 November 2017

Published online: 22 December 2017

Editor: A. Minelli

\section{Online supplementary information}

SI1. A list of all Pulmonata samples used.

SI2. Representative scanning electron micrographs of details of the sperm mass inside spermatophores for each of the Pulmonata samples in SI1.

SI3. A list of all Passeriformes samples used.

SI4. Scanning electron micrographs of representative sperm cells for each of the Passeriformes samples in SI3. 